\title{
Service-Learning Pedagogy: Benefits Of A Learning Community Approach
}

\author{
Brooke A. Flinders, Miami University, USA
}

\begin{abstract}
Service-learning is, by nature, continually evolving. Seifer (1996) stressed the importance of partnerships between communities and schools, and stated that reflection should facilitate the connection between practice and theory, and lead to critical thinking. Before these reflective activities occur, however, much can be done to maximize student impacts and facilitate critical thinking. When students are included as partners, within a learning community, they can experience significant professional development through the mentoring and modeling of professional behaviors, by faculty members. During a three month pilot, a team of junior-level, undergraduate nursing students joined together, in one such learning community, called "FOCUS". The common agenda was to update evidence-based program materials, prepare for a federally-funded, five-year study, and to begin educating local females, regarding pregnancy and sexually transmitted infection (STI) strategies. This article reviews key impacts for the pilot team, and explores student-identified outcomes, in reflection of their learning community experience.
\end{abstract}

Keywords: Learning Communities; Partnership; Civic Engagement; Experiential Learning; Scholarship of Teaching and Learning

\section{INTRODUCTION}

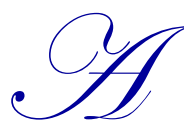

ccording to Bringle and Hatcher's classic work (1996), service learning occurs when students are engaged in an organized service activity that meets a community need. A common problem for educators, when incorporating service-learning in the clinical setting, is moving out of the way of our students, and allowing them to make decisions, implement ideas, and evaluate practice, for themselves. Often, we become so focused on the service that we forget about the learning.

Rather than faculty leading the way, and controlling for all possible disasters, students should be empowered through collaborative and cooperative faculty-facilitated learning communities (Flinders, et. al., 2012). When educators create a safe, learning community climate, students are able to prepare and practice in a low-stakes environment, receive feedback, and can go on to provide service with confidence and with competence.

\section{Student Learning Communities}

In 1995, Barr and Tagg discussed the "learning paradigm", and stressed the importance of creating environments that bring students to "discover and construct knowledge for themselves". If educators are willing to step back as service-learning directors, in order to become learning community team members, students are enabled to step up and to more deeply engage in their own service. A learning community is ideal for allowing students to "discover and construct knowledge for themselves". It provides support and needed structure, allows for faculty and peer input, guides meaningful reflection, and can deliberately avoid confining the students' focus to the completion of a particular class assignment.

Wenger (1998) outlined foundational principles of "communities of practice", in summary, by stating that participants must 1) be engaged in "joint enterprise", some compelling purpose or project that draws them together, 2) have common access to shared resources, and 3) maintain relationships through "mutual engagement" in trustbuilding activities. 
In spring, 2011, one such learning community, in an undergraduate nursing program, was created. The common agenda was to serve as a pilot team for a teenage pregnancy prevention program. Ten, junior-level nursing students volunteered to meet on a weekly basis, to review the curriculum, to implement updates and ensure that current evidence-based practice measures were included, and to present the eight hour program to teens, in four community-based settings. Finally, members of this pilot team were included in the evaluation and dissemination of program results, and through presentations at professional conferences.

The students were selected for one of two positions: 1) Undergraduate Associates (UAs), who contributed thirty hours per semester, through the university honor's program, or 2) Research Assistants (RAs), who contributed twenty hours, per week.

\section{METHODS}

Eight undergraduate students fulfilled learning community and reflection requirements. Quantitative data, via likert scale, was gathered at the end of the pilot period. Undergraduates were asked to rate their experiences, 1-5, with 5 being the greatest, in areas identified as being impacted by service-learning opportunities (Callister and Hobbins-Garbett, 2000). These areas include: awareness of unmet community needs, critical thinking, personal satisfaction, preparation for practice, and professional development.

Qualitative data was gathered, using an exit survey, modified from Bystrom's "Post -Program Interviews for Learning Community Faculties”, (Washington Center Assessment Handbook Writing Group, 1994). Guided reflection focused on accomplishments, things that went well, the most difficult aspects of involvement, and selflearning.

Questions included in these surveys were: 1) Did you meet the objectives and outcomes you set for yourself at the beginning of the semester? Why or why not? 2) Did the responsibilities and roles you assumed match your expectations? Why or why not? 3) What was the most rewarding aspect of the experience? 4) How have you grown or developed as a result of the experience? and 5) what was the biggest contribution to your learning?

Sample qualitative data was originally scanned, with the use of NVivo software, and items from both UA reflections and RA reflections were coded, word-by-word, to identify key themes. All key words were developed as "nodes" within the system, and were then used to systematically analyze the two reflective activities.

Summary of analyzed sources, number of nodes coded within each source, and number of coding incidents are summarized in Table 1.

Table 1: Source Summary

\begin{tabular}{|l|c|c|}
\hline \multicolumn{1}{|c|}{ Source } & Number of Coded Nodes & Number of Coding Incidents \\
\hline UA Reflections ( $\mathrm{n}=5)$ & 22 & 71 \\
\hline RA Reflections $(\mathrm{n}=3)$ & 16 & 76 \\
\hline Q1: What went well? & 23 & 13 \\
\hline Q2: Did roles match expectations? & 8 & 6 \\
\hline Q3: Most rewarding aspect? & 6 & 31 \\
\hline Q4: How have you grown? & 14 & 73 \\
\hline Q5: Biggest contribution? & 20 & \\
\hline
\end{tabular}

\section{FINDINGS}

\section{Quantitative Ratings via Likert Scale}

The first reportable findings come from a likert scale, quantifying feedback from eight participants, and based upon service-learning impact categories (Callister and Hobbins-Garbett, 2000). Results, on a five-point scale, ranged from 4.75-5.0 (Table 2). Highest scores (5.0) came in the categories of "personal satisfaction" and "professional development". The lowest score (4.75) was provided for the category of "feelings of preparedness for practice". The combined project mean was 4.90 . 
Table 2: FOCUS Program Pilot Experience

\begin{tabular}{|l|c|}
\hline \multicolumn{1}{|c|}{ Student Ratings, 1-5, 5 is highest rating } & Mean \\
\hline $\mathbf{N}=\mathbf{8}$ & 5.00 \\
\hline Personal Satisfaction & 5.00 \\
\hline Professional Development & 4.88 \\
\hline Critical Thinking Skills & 4.88 \\
\hline Awareness of Unmet Community Needs & 4.75 \\
\hline Feelings of Preparedness for Practice & \\
\hline Combined Project Mean & 4.90 \\
\hline
\end{tabular}

\section{Qualitative Analysis}

\section{Word Tree}

The first step, in analyzing the service-learning reflections, was to identify key themes. A word tree was developed, in order to visualize the most commonly used words and to examine the connections between overarching concepts of the reflections (Figure 1).

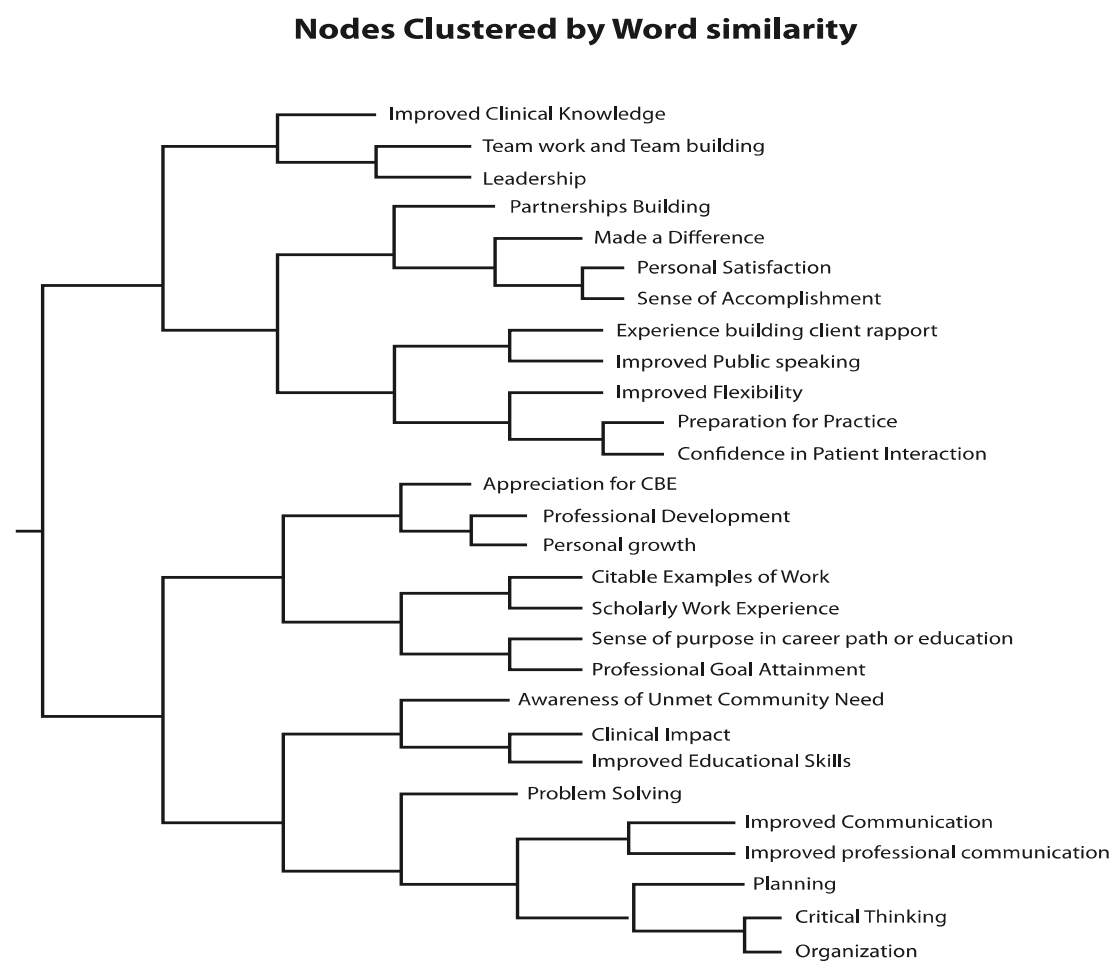

Figure 1

\section{Theme Categorization}

Next, themes (nodes) were categorized. While the clustered nodes (Figure 1) were helpful for overall theme identification, it was determined that each of the nodes fit within the five impact areas, originally evaluated via the likert scale. 2,837 words were included in the sample, and 28 total categories/subcategories were identified.

The number of references for each impact category and for each node subcategory was calculated, for comparison (Table 3). 
Table 3: Impact Factors and Associated Node Sub-Categories

\begin{tabular}{|c|c|c|}
\hline Impact Category & Node Subcategory & Number of References \\
\hline Awareness of Unmet Community Needs & & 19 Total \\
\hline \multirow{5}{*}{ Critical Thinking } & & 19 Total \\
\hline & Organization Improved & 10 \\
\hline & Planning Improved & 1 \\
\hline & Problem Solving & 6 \\
\hline & Time Management & 2 \\
\hline \multirow[t]{3}{*}{ Personal Satisfaction } & & 20 Total \\
\hline & Made a Difference & 2 \\
\hline & Sense of Accomplishment & 11 \\
\hline \multirow[t]{10}{*}{ Preparation for Practice } & & 59 Total \\
\hline & Clinical Impact & 5 \\
\hline & Confidence with Client Interactions & 11 \\
\hline & Experience with building Rapport with Clients & 4 \\
\hline & Improved Clinical Knowledge & 6 \\
\hline & Improved Communication & 5 \\
\hline & Improved Educational Skills & 8 \\
\hline & Improved Flexibility & 10 \\
\hline & Partnership Building & 2 \\
\hline & Teamwork/Team Building & 19 \\
\hline \multirow[t]{8}{*}{ Professional Development } & & Total 60 \\
\hline & Appreciation for Community-Based Care & 5 \\
\hline & Citable Examples of Work & 8 \\
\hline & Improved Professional Communication & 9 \\
\hline & Improved Public Speaking & 13 \\
\hline & Leadership & 5 \\
\hline & Personal Growth & 14 \\
\hline & Professional Goal Attainment & 6 \\
\hline
\end{tabular}

A summary of findings for all sources, by impact area, is noted in Figure 2. "Professional Development" and "Preparedness for Practice" categories were the nodes most coded, during analysis of the reflective journaling.

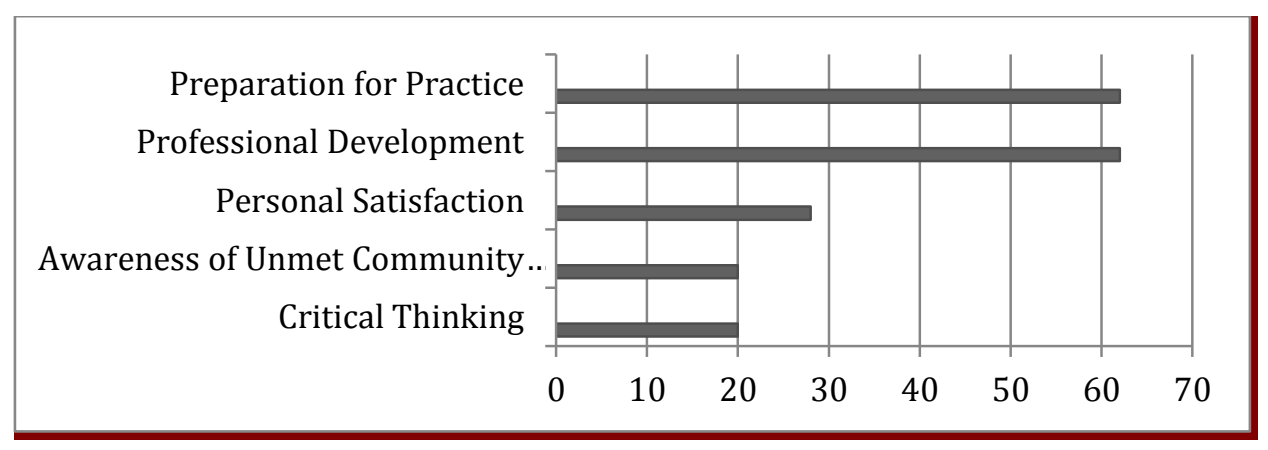

Figure 2: Coding by Node

\section{Qualitative Samples}

Representative student quotes have been selected, to capture overall, student-identified impacts. Several themes were noted, when quotes were reviewed more holistically: 1) professional development, 2) awareness of unmet community needs, 3) appreciation of partnership/learning community approach, 4) exposure to and appreciation for community-based care, 5) experience in building a rapport and 6) recognizing and overcoming bias (Tables 4-9). Of these identified themes, five of the six impact areas validated by the systematic review and coding methods. Only "recognizing an overcoming bias" emerged as a new theme, when student quotes were reviewed for overarching ideas. 
Table 4: Selected Student Quotes Regarding Professional Development Theme

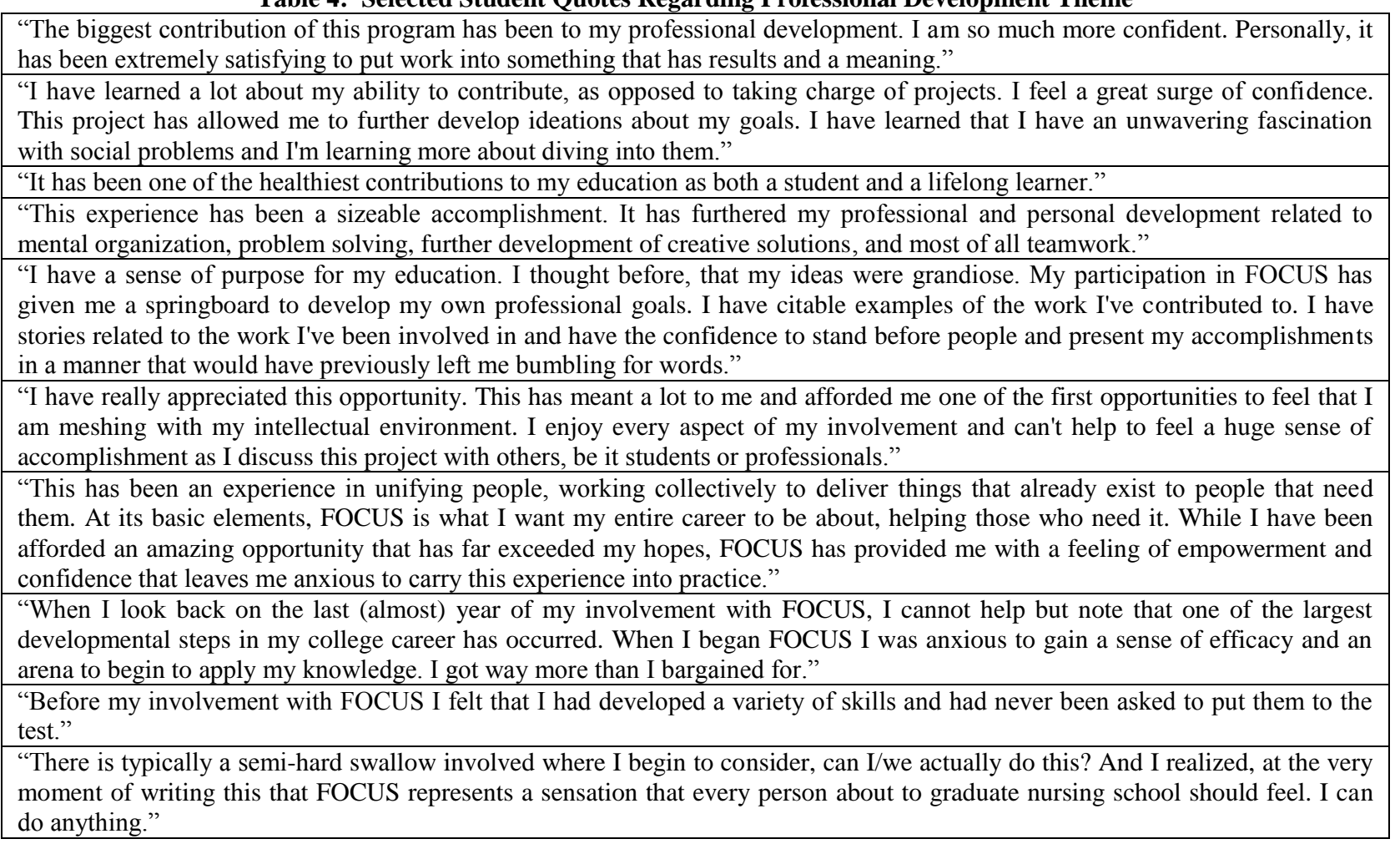

Table 5: Selected Quotes Regarding Awareness of Unmet Community Needs Theme

"I feel my future career in nursing will be hugely impacted by this experience. I have gained a new glimpse of a large population
of at risk peoples, applied nursing skills, attempted to attack a pressing social problem and continued to develop skills that are
invaluable in my career. I think I'll be a better nurse because of FOCUS."
"This experience further enhanced my knowledge of community needs. It made me realize that there is so much more to nursing
than working on a floor or on a unit within a hospital. I have the chance to make a huge difference in the lives of many people
once I graduate and I am excited for that opportunity!"

Table 6: Selected Quotes Regarding Appreciation of Partnership (Learning Community) Approach Theme

"The manner in which the program is designed allows students to take charge of their learning by which the program is designed allows students to take charge of their learning by organizing and delegating work within the group to come to a unified group goal. This method of learning places greater responsibility on the student and allows the student to learn and grow with the help and direction of the group. I feel that this method of learning fosters independence, which in turn nurtures self esteem and personal growth."

"Our collective efforts have snowballed into something that is continually adapting but already seemingly sustainable."

Table 7: Selected Quotes Regarding Exposure to/Appreciation for Community-Based Nursing Care Theme

"I feel that I have grown personally and have become more comfortable interacting with the community. There is a great level of satisfaction knowing that many young girls have learned from their involvement in the program and may now be more empowered to make healthy life choices for themselves."

"The greatest thing I have accomplished in working on FOCUS is discovering my passion for community health and interest in finding ways to meet the needs of our community. Before this experience I never would have imagined myself in community health in any way, but now I hope to keep it as a part of my life throughout my career." 
Table 8: Selected Quotes Regarding Experience in Building Rapport Theme

"Finally the thing I believe that will most help us in our nursing careers is learning to provide a comfortable, laid back atmosphere to promote learning. No matter what age a person is if they feel uncomfortable with their nurse they are never going to ask the questions they should ask or share the information they need to share. I think this program showed us that if you are non-judgmental and open to interaction with the people you are teaching that so much more can be learned. Creating the right atmosphere and environment is always mentioned in all our books and FOCUS has helped put it in real life so we as students can see what it is like."

"I have learned that I do have the capability to make people comfortable around me and that I can be a part of something that really does make a difference for others."

"It was important to establish approachability on the first day and to let participants know we were creating a non-judgmental environment. This allowed for participants to be open and honest. It enhanced their willingness to listen and actively participate in the program. Approachability is key when presenting this content of material and especially to the target age group. The participants have to feel they can talk to you, the presenter, in order to fully engage the material."

Table 9: Selected Quotes Regarding Learning to Recognize and Overcome Bias Theme

"I see that social boundaries can be worked around or even eliminated; outcomes that depend largely on my ability to address the individual with respect."

"I have learned that you can't have biases or be judgmental and expect to help people. Your job is to provide them with the care they need no matter what their background may be. Also, it's not up to you to decide if someone's lifestyle is good enough or not. Everyone is different and different things work for different people."

\section{DISCUSSION}

One way to significantly impact learning outcomes and to assist students in synthesizing their learning is to create a learning community environment that provides support, structure, and guidance to each learner. Because students function within a learning community, side-by-side with their professor and peers, they are given an opportunity to work as a team, in creating their own paths and in finding a common direction.

The nursing students in the "FOCUS" learning community saw themselves as empowered team members. Because the faculty member set out to create a community of learners, rather than to delegate tasks and supervise, the students engaged in critical thinking, and identified significant impacts in the areas of professional development and personal satisfaction. They came out of the experience with appreciation for their own knowledge and with a sense of accomplishment.

Preparedness for practice, professional development, and personal satisfaction were the areas that student identified the most impact. One surprising theme noted in this study, was "improved flexibility". Students discussed difficulty with being "allowed" to work autonomously, and with having less guidance and direction in making decisions. These feelings of increased flexibility are likely tied to success and validation that they truly are capable, and from movement from the diverging and assimilating learning approaches to converging and accommodating learning approaches, described by Kolb in his "Experiential Learning Cycle" (1984). Because students were expected to think and do, rather than feel or watch, they were successful.

The "Partnership Model" developed for this learning community (Flinders, Carlascio, Gilb, \& Nicholson, 2013), and the theoretical framework for "bounded communities" (Wilson, Ludwig-Hardman, Thornam, and Dunlap, 2004), became embedded within a required 300 level nursing course, beginning fall 2011. On-going evaluation for validation of this study and for expanded exploration of student impacts will continue.

\section{ACKNOWLEDGEMENTS}

This project was supported by Grant Number TP1AH000050-01-01 from the U.S. Department of Health and Human Services, Office of Adolescent Health. The content of this manuscript is solely the responsibility of the authors and does not necessarily represent the official views of the U.S. Department of Health and Human Services. 


\section{AUTHOR INFORMATION}

Brooke Flinders is a graduate of Miami University and Frontier School of Midwifery and Family Nursing. After practicing as a nurse-midwife, Brooke began a tenure-track position in Miami University's Department of Nursing, in 2007. Her passion for women's health and undergraduate education has merged into a program, funded by the U.S. Department of Health and Human Services, for over two million dollars. This service-learning program, in collaboration with the Hamilton YWCA, involves evidence-based STI and teenage pregnancy prevention strategies, and is being implemented, utilizing third year nursing students as community educators. E-mail: flindeba@muohio.edu

\section{REFERENCES}

1. Barr, R., \& Tagg, J. (1995). From teaching to learning: A new paradigm for undergraduate education. Change, 27(6). Retrieved January 19, 2011 from: http://pages.cs.wisc.edu/ nordheim/Barr and Tagg.pdf

2. Bringle, R.G., Hatcher, J.A. (1996). Implementing service learning in higher education. Journal of Higher Education, 67(2).

3. Callister, L.C., Hobbins-Garbett, D. (2000). "Enter to learn, go forth to serve": Service learning in nursing education. Journal of Professional Nursing, 16 (3), 177-183.

4. Flinders, B., Carlascio, C., Gilb, K., \& Nicholson, L. (2013). The Partnership Model for Service-Learning Programs: A Step-by-Step Approach. American Journal of Health Sciences, 4(2).

5. Flinders, B., Carlascio, A., Gilb, K., and Nicholson, L. (Presented January 2, 2012). Cooperative learning in action: Moving toward authentic partnership in service-learning. The 2012 Orlando International Academic Conference. Orlando, Florida, USA. Paper retrieved from: http://conferences.cluteonline.com/index.php/IAC/2012DW/paper/viewFile/826/834

6. Flinders, B., Session presented November 17, 2012: The "Partnership model" for service-learning: A fresh approach allowing for collective impact. Lilly International Conference on 'College Teaching. Abstract retrieved from: http://celt.muohio.edu/lillycon/presenters.php?session=1948\&year=2012

7. Kolb D. (1984). Experiential learning: experience as the source of learning and development. Englewood Cliffs, New Jersey: Prentice Hall.

8. Seifer, S.D. (1998). Service-learning: Community-campus partnerships for health professions education. Academic Medicine, 73(3), 272-277.

9. Washington Center Assessment Handbook Writing Group (1994). Bystrom: Assessment in and of collaborative learning. Retrieved June 1, 2011 from: www.evergreen.edu/washcenter/resources/acl/iib.html

10. Wenger, E. (1998). Communities of Practice: Learning, meaning, and identity. Cambridge, UK: Cambridge University Press.

11. Wilson, B., Ludwig-Hardman, S., Thornam, C., \& Dunlap, J. (2004). Bounded Community: Designing and Facilitating Learning Communities in Formal Courses. The International Review Of Research In Open And Distance Learning, 5(3). Retrieved from http://www.irrodl.org/index.php/irrodl/article/view/204/286 
NOTES 